\title{
Enfrentamento à LGBTIfobia, Afirmação Ético-política e Regulamentação Profissional: 20 anos da Resolução CFP no 01/1999
}

\author{
Luan Carpes Barros Cassal ${ }^{1}$ \\ ${ }^{1}$ The University of Manchester, Manchester, Reino Unido. $\quad{ }^{2}$ Universidade Federal Fluminense, Niterói, Brasil. \\ Pedro Paulo Gastalho de Bicalho ${ }^{3}$ \\ ${ }^{3}$ Universidade Federal do Rio de Janeiro, Rio de Janeiro, Brasil.
}

Resumo: O presente artigo analisa, de maneira crítica, os 20 anos da Resolução no 01/1999 do Conselho Federal de Psicologia. Tal documento regulamenta o exercício profissional sobre orientação sexual; mais exatamente, veta práticas de patologização e discriminação, e incentiva o enfrentamento ao preconceito e à violência. Primeiramente, discutimos como a Resolução foi objeto de debate legislativo e esteve cerceada pelo judiciário, apesar de sua imensa visibilidade, força política e capacidade de garantia de direitos humanos - ou, talvez, justamente por isso. Em seguida, analisamos o objetivo de tais ações - autorizar práticas que tentam reverter a homossexualidade: elas não têm fundamentos no atual conhecimento psicológico, configuram exercício de tortura e produzem efeitos de intenso sofrimento e adoecimento. Posteriormente, debatemos desafios e possibilidades para posicionamento ético do exercício profissional da Psicologia com homossexualidades em diferentes campos de atuação (educação, justiça e política de saúde) de forma a enfrentar as patologizações. Por fim, interrogamos a votação do Supremo Tribunal Federal sobre a criminalização da LGBTIfobia a partir da criminologia crítica, em dialogo com os efeitos da Resolução n ${ }^{\circ} 01 / 1999$. Concluímos que este documento, ainda que insuficiente para eliminar as práticas de LGBTIfobia, segue um instrumento relevante para uma Psicologia de garantia dos direitos humanos.

Palavras-chave: Psicologia, Homossexualidade, LGBTIfobia, Resolução CFP 01/1999.

\section{Coping with LGBTIphobia, Ethical-political Affirmation and Professional Regulation: 20 Years of CFP Resolution 01/1999}

\begin{abstract}
This article critically analyzes the 20 years of Resolution no 01/1999 of the Federal Council of Psychology. This document regulates the professional exercise on sexual orientation; more precisely, it prohibits pathologization and discrimination practices, and also encourages confronting prejudice and violence. Firstly, we discuss how the resolution has been subject of legislative and judiciary actions, despite its immense visibility, political power and capacity to guarantee human rights - or, perhaps, precisely because of them. Then, we analyze the purpose of such actions - to authorize practices trying to reverse homosexuality: they do have not basis in current psychological knowledge, configuring a torture exercise and producing intense suffering and illness. Subsequently, we discuss challenges and possibilities for ethical psychological practices with homosexualities in different fields (education, justice and health policy) confronting pathologizations. Finally, we use the critical criminology to question the Federal Supreme Court decision on the LGBTIphobia criminalization, in dialogue with the Resolution's effects. We conclude that even if this document did not eliminate LGBTIphobia practices, is a relevant strategy for psychology to ensure human rights.
\end{abstract}

Keywords: Psychology, Homosexuality, LGBTIphobia, Psychology Resolution 01/1999. 


\title{
Enfrentamiento a la LGBTIfobia, Declaración Ético-política y Regulación Profesional: 20 Años de la Resolución CFP 01/1999
}

\begin{abstract}
Resumen: Este artículo analiza críticamente el vigésimo aniversario de la Resolución No. 01/1999 del Consejo Federal de Psicología. Este documento regula el ejercicio profesional sobre orientación sexual; más precisamente, veta las prácticas de patologización y discriminación, y alienta la confrontación de prejuicios y violencia. Primero, discutimos cómo la Resolución fue objeto de debate legislativo y estuvo rodeada por el poder judicial, a pesar de su inmensa visibilidad, fortaleza política y capacidad para garantizar los derechos humanos, o quizás, precisamente por eso. Luego analizamos el propósito de tales acciones: autorizar prácticas que intentan revertir la homosexualidad: no tienen base en el conocimiento psicológico actual, configuran ejercicio de tortura y producen efectos de sufrimiento y enfermedad intensos. Posteriormente, discutimos los desafíos y las posibilidades para el posicionamiento ético de la práctica profesional de la psicología con las homosexualidades en diferentes campos (educación, justicia y política de salud) para enfrentar patologías. Finalmente, cuestionamos el voto de la Corte Suprema sobre la criminalización de la fobia LGBTI por la criminología crítica, en diálogo con los efectos de la Resolución 01/1999.Concluimos que este documento, aunque insuficiente para eliminar las prácticas de LGBTIfobia, sigue una herramienta relevante para una psicología que garantice los derechos humanos.
\end{abstract}

Palabras clave: Psicología, Homosexualidad, LGBTIfobia, Resolución PPC 01/1999.

\section{Introdução}

Em 2018, foi lançada uma campanha publicitária do Governo Federal brasileiro com o slogan "O Brasil voltou, 20 anos em 2" (Rodrigues, 2018). Rapidamente, tornou-se motivo de chacota em redes sociais e outros meios de comunicação: o verbo voltar poderia remeter a retorno à direção correta, mas também a retrocesso. Mais ainda, nas redes sociais e especialmente em links de internet, a vírgula era omitida e ficava mais evidente o processo de desmonte das políticas econômicas e direitos sociais, em muito parecendo com a década de 1990. Será que retrocedemos?

Há 20 anos, o Conselho Federal de Psicologia (CFP) promulgou a Resolução no 1 (1999), que "Estabelece normas de atuação para os psicólogos em relação à questão da Orientação Sexual". Considerada extremamente progressista à época, a Resolução sofreu diversos ataques ao longo dos últimos anos. Seria pelas forças que estão a produzir retrocessos?
A Resolução completa 20 anos de existência com uma trajetória de lutas e resistências. Em uma inspiração genealógica ao olhar para a história (Foucault, 1979), faz-se necessário perceber as condições para emergência das lutas e embates do presente. O presente texto pretende analisar tensões que a Resolução estabelece atualmente para a Psicologia e a sociedade. Para tanto, inspiramo-nos na cartografia, metodologia de pesquisa que pretende acompanhar processos mais do que representar objetos, de forma a mapear as forças e formas estabelecidas em um determinado campo de investigação, construindo o método durante o caminhar (Passos, \& Barros, 2009). Primeiramente, apresentaremos questões sobre o Sistema Conselhos de Psicologia ${ }^{1}$ e a regulamentação das práticas de psicólogas e psicólogos. Em seguida, discutiremos os limites para práticas serem reconhecidas como exercício profissional da Psicologia. Posteriormente, o texto apresentará as possibilidades de tomar

\footnotetext{
${ }^{1}$ Ao tratar do CFP e dos Conselhos Regionais de Psicologia (CRP), utiliza-se essa expressão. Importante destacar que a criação e publicação de resoluções é atribuição do CFP, mas dizem respeito e devem ser cumpridas por todo o Sistema Conselhos de Psicologia (Conselho Federal de Psicologia, s.d.).
} 
a Resolução como diretriz ética em diferentes campos de atuação. A seguir, analisaremos as relações da Psicologia com o julgamento sobre a criminalização da LGBTIfobia pelo Supremo Tribunal Federal (STF). Por fim, consideraremos alguns embates atuais e a urgência de posicionamentos éticos.

\section{Resolução CFP no $01 / 1999$ e normativas profissionais}

O CFP, conforme previsto pela Lei no 5.766/1971, tem por obrigação fiscalizar, orientar e disciplinar o exercício profissional de psicólogas e psicólogos em território brasileiro. Uma das maneiras de cumprir suas funções é através da promulgação de Resoluções, que determinam os limites da ética profissional. Estes documentos regulamentam, por um lado, o que não pode ser feito (posto que não é reconhecido como prática de Psicologia e, portanto, não pode ser exercida em nome da profissão) e, por outro, como fazer o que não está proibido (a forma de realizar atividades de forma ética). Normas estritas delimitam o território da profissão; orientações éticas indicam o modo a atuar dentro desse território.

A Resolução $n^{\circ} 1$ (1999) foi elaborada após denúncias feitas pelo Grupo Gay da Bahia (GGB) de práticas psicológicas com a promessa declarada de converter o desejo sexual da homossexualidade para a heterossexualidade. O CFP avaliou que não tinha instrumentos éticos para regular tal matéria e, através de debates públicos com profissionais, pesquisadores e militantes, elaborou a referida Resolução, que "Estabelece normas de atuação para os psicólogos em relação à questão da Orientação Sexual”. Mais especificamente, o documento proíbe práticas de patologização de sujeitos e práticas homoeróticas ${ }^{2}$, bem como a manifestação de discursos e a colaboração com eventos que tenham esse mesmo caráter. Vale destacar que a resolução atingiu imensa visibilidade, "pois ao mesmo tempo que essa Resolução muito nos orgulha, por tudo aquilo que ela representa e afirma, ela tam- bém é a resolução mais atacada do Sistema Conselhos de Psicologia, ao longo desses 20 anos" $^{3}$. De fato, a resolução foi questionada em diferentes instâncias.

Em 2010, foi interposto um mandado de segurança, no âmbito do processo $\mathrm{n}^{\circ}$ 02417041.2009.4.01.3400, alegando inconstitucionalidade da Resolução. Em 2011, o Projeto de Decreto Legislativo 234 intentou sustar os efeitos da resolução, sob a justificativa que, "ao restringir o trabalho dos profissionais e o direito da pessoa de receber orientação profissional, por intermédio do questionado ato normativo, extrapolou o seu poder regulamentar". Ainda em 2011, o Ministério Público Federal (MPF) propôs a Ação Civil Pública no 0018794-17.2011.4.02.5101, solicitando anulação da Resolução, sob a alegação de que o CFP exorbitou do poder regulamentar, violando inúmeros princípios e regras constitucionais, como o da legalidade, o direito fundamental ao livre exercício profissional, o princípio da dignidade da pessoa humana e a liberdade de manifestação do pensamento, dentre outros. O pedido de antecipação dos efeitos de anulação foi feito pelo MPF, pois entendeu que a Resolução causaria danos para psicólogas e psicólogos - que supostamente estariam impedidos de exercer a profissão livremente-, e para os homossexuais que voluntariamente pudessem procurar auxílio psicológico para se afirmar como heterossexuais, por estarem insatisfeitos com sua orientação. Essa ação foi transitada em julgado em favor da perfeita legalidade da Resolução.

Posteriormente, em 2014, o Projeto de Decreto Complementar $n^{\circ}$ 1.457/2014 dispôs sustar os efeitos da resolução, sob a justificativa de que a normativa declara que a homossexualidade não constitui doença, nem distúrbio e nem perversão. Para o autor do decreto, este seria posicionamento político, sem base científica e que desconsideraria substanciais estudos no campo da Psicologia e da Psicanálise que indicariam o contrário. Afirma, ainda, que a resolução teria por objetivo perseguir psicólogos ligados a gru-

\footnotetext{
${ }^{2}$ Importante destacar que, à época, a discussão sobre orientações sexuais era especialmente associada à homossexualidade e heterossexualidade. Por um lado, movimentos sobre gênero e sexualidade reivindicam, atualmente, identidades diversas como bissexuais (que expressam desejo por pessoas de gênero masculino e feminino), pansexuais (que expressam desejo por pessoas de quaisquer gêneros, inclusive aquelas que não se identificam como nem masculinas, nem femininas) e assexuais (que não expressam ou vivenciam desejos sexuais, ou que não associam relações afetivas e relacionamentos à sexualidade, dentre outros), e estes não estão textualmente listadas no texto. Por outro, a direção ética da Resolução trata da proteção às orientações sexuais e sua não patologização. Nesse sentido, ainda que seu texto reflita um determinado instante histórico, esse documento deve ser lido conforme o momento atual, abarcando todas as identidades e orientações sexuais reconhecidas por movimentos sociais e conhecimento científico em Psicologia.

${ }^{3}$ Fala do conselheiro do CFP, Pedro Bicalho, recuperado de https://site.cfp.org.br/resolucao-01-99-completa-20-anos/
} 
pos religiosos que oferecem tratamento para o dito "homossexualismo [sic]". Em 2016, o Projeto de Lei no $4.931 / 2016$ propôs autorizar o profissional de saúde mental a atender e aplicar terapias e tratamentos visando auxiliar a mudança da orientação sexual, deixando o paciente de ser homossexual para ser heterossexual, desde que corresponda ao seu desejo. Tal lei anularia os efeitos da Resolução no 1 (1999).

Ainda em 2016, o Projeto de Decreto Legislativo da Câmara (PDC) no 539/2016 pediu a sustação dos efeitos da Resolução no 1 (1999) do CFP, com a justificativa de que, por meio desta, o CFP estaria arrogando para si competência do Congresso Nacional e direito de legislar, sob o manto da Lei $n^{\circ}$ 5.766, de 20 de dezembro de 1971, rompendo assim os direitos fundamentais. O PDC teve por objetivo supostamente estabelecer e conservar a competência do congresso nacional, alegando que a referida competência vem sendo usurpada por poderes que não têm como atividade típica a alteração de normas legais.

Finalmente, em 2017, um grupo (composto por 22 psicólogas e um psicólogo) entrou com a ação popular $\mathrm{n}^{\circ}$ 1011189-79.2017.4.01.3400, com pedido de liminar objetivando a suspensão dos efeitos da Resolução. Alegavam que a resolução seria um ato de censura, que impediria os psicólogos de desenvolverem estudos, atendimentos e pesquisas científicas acerca dos comportamentos e práticas homoeróticas; constituiria, assim, um ato lesivo ao patrimônio cultural e científico do país. Tal ação, acatada pelo Juiz Federal da $14^{\text {a }}$ Vara (Distrito Federal), Waldemar Claudio de Camargo, resultou em liminar e posterior sentença que descaracterizou a resolução pois, apesar de mantê-la, na íntegra, a decisão judicial determinou ao CFP que a interpretasse de modo a não proibir a prática psicológica de reorientação sexual para "egodistônicos que desejassem tal mudança". Tal decisão foi mantida até o mês de abril de 2019, quando liminar do STF em favor de pedido de reclamação do CFP desfez os efeitos da sentença. Até a finalização deste texto, ainda não havia sido marcado julgamento do STF sobre a matéria decidida em forma de medida liminar.

É importante assinalar que a Resolução no 1 (1999) foi a primeira regulamentação do CFP sobre esta matéria. Entretanto, o Código de Ética Profissional (Conselho Federal de Psicologia [CFP], 2005) vigente foi promulgado através da Resolução no 10 (2005) do CFP e incorporou a mesma orientação daquele documento. Especificamente, o artigo $2^{\circ}$ veda a pessoas profissionais de Psicologia: "b) Induzir a convicções políticas, filosóficas, morais, ideológicas, religiosas, de orientação sexual ou a qualquer tipo de preconceito, quando do exercício de suas funções profissionais".

Além disso, conforme decisões do Conselho Nacional de Psicologia, nos últimos anos o CFP construiu e promulgou resoluções para garantia do direito às identidades de gênero de pessoas trans. Para psicólogas e psicólogos, a Resolução no 14 (2011) estabeleceu a possibilidade de inclusão do nome social na Carteira de Identidade Profissional (CIP) no campo "observação", e uso do mesmo em materiais públicos e de divulgação. Essa solução, bastante limitada (pois mantinha o nome de registro em destaque), foi aperfeiçoada com a Resolução no 10 (2018), que cria um campo na CIP para o nome social, além de garantir o seu uso e o reconhecimento da identidade de gênero autodeterminada em todos os procedimentos e espaços do Sistema Conselhos de Psicologia.

De forma mais ampla, o CFP estabeleceu a diretriz ética na atuação profissional da Psicologia com pessoas travestis e transexuais através da Resolução $n^{\circ} 1$ (2018). Com perspectiva similar à 1 (1999), este documento proíbe práticas de patologização e discriminação, e exige de profissionais o enfrentamento da transfobia e do preconceito:

Esta Resolução é fruto de diversas discussões no âmbito do Sistema Conselhos de Psicologia e apresenta importantes afirmações ético-políticas acerca da transexualidade e da travestilidade, assim como de outros conceitos fundamentais para o debate acerca da despatologização das identidades trans e da garantia de autonomia de cada sujeito para a autodeterminação em relação às expressões e identidades de gênero. $\mathrm{O}$ texto da resolução é voltado ao exercício profissional das psicólogas e psicólogos e prevê práticas contrárias ao preconceito e à discriminação de pessoas transexuais e travestis (Cavalcanti, Carvalho, \& Bicalho, 2018, p. 234).

A Resolução $n^{\circ} 1$ (2018) foi elaborada com a participação de pessoas psicólogas, pesquisadoras e militantes, e publicada no Dia da Visibilidade Trans, de forma a reiterar o direito à autodeterminação das pessoas trans. Entretanto, poucos dias depois, o MPF 
de Goiás ingressou com uma ação civil pública contra a Resolução e o CFP, posteriormente recusada pela justiça federal por questões formais, sem julgamento do conteúdo (Cavalcanti et al., 2018).

Portanto, a Resolução no 1 (1999) não é, atualmente, o único documento da Psicologia brasileira a legislar sobre gênero e sexualidade. Entretanto, as muitas tentativas de suspensão ou anulação dessa regulamentação indicam sua imensa importância histórica e política. Mais ainda, as propostas da e para a profissão, escolhidas democraticamente nos Congressos de Psicologia e no CNP, são pela sua manutenção e a criação de novos documentos para garantia de direitos, como as resoluções sobre transexualidades e travestilidades. Então, a tentativa de derrubada da Resolução através de procedimentos e instituições externas ao Sistema Conselhos de Psicologia é uma tentativa autoritária, na contramão dos processos democráticos instituídos. As disputas devem acontecer através das propostas de tese para o CNP, posto que ali se determina a direção que o Sistema Conselhos de Psicologia seguirá durante três anos. A luta pela manutenção da 01 (1999) (assim como pela Resolução n. 1, 2018) condiz com as decisões da categoria. Essa perspectiva que gerou o documento há 20 anos segue vigente porque a Psicologia brasileira continua sendo contra qualquer forma de violação e violência.

\section{O contexto da proibição de práticas que tentam reverter a homossexualidade}

É importante identificar alguns contextos que fazem com que a Resolução no 1 (1999) seja muito relevante para a Psicologia, o campo de Direitos Humanos e a saúde mental de sujeitos que possuem uma orientação sexual não heteronormativa. Vale ressaltar que os ataques que a Resolução no 1 (1999) sofreu (discutidos na seção anterior) foram marcados fortemente por motivação religiosa de sujeitos evangélicos. A pesquisa de Marcelo Tavares Natividade (2006), antropólogo brasileiro, é indispensável para compreender tais ataques. $\mathrm{O}$ autor realizou um levantamento bibliográfico e uma etnografia em pastorais evangélicas que tentam reorientar o desejo homossexual.

A partir de sua contribuição, destacamos que as práticas que tentam reorientar o desejo homossexual se configuram como práticas de tortura. Isso é verificado, por exemplo, no Relatório de Inspeção Nacional em Comunidades Terapêuticas, realizado pelo CFP, em parceria com o MPF e o Mecanismo Nacional de Prevenção e Combate à Tortura - MNPCT (Conselho Federal de Psicologia [CFP] \& Ministério Público Federal [MPF], 2018). E, ao final desta seção, faremos uma breve discussão sobre a tentativa de se utilizar o DSM e seu diagnóstico de orientação sexual egodistônica como formas de justificar cientificamente as práticas de tortura que tentam reverter a homossexualidade. Mais ainda, estas são calcadas exclusivamente em valores morais e crenças pessoais, o que descaracteriza completamente a ética e a própria cientificidade da Psicologia.

Natividade (2006) identifica três concepções recorrentes que caracterizam a homossexualidade nas pastorais evangélicas hegemônicas e fundamentalistas. Esta orientação sexual é tomada como um comportamento aprendido, um problema espiritual e antinatural. Em termos de discussão, o autor faz um estudo bibliográfico e etnográfico demonstrando como essas concepções são produzidas e ratificadas. Desta maneira, a homossexualidade seria um estado psicossocial produzido por experiências negativas na infância, tais como: abuso sexual, socialização em famílias ditas desestruturadas, e ausência de modelos firmes de masculino e feminino. Esses fatores, combinados ou não, gerariam uma identificação com o gênero oposto ao atribuído (tido como natural), produzindo assim, o estado homossexual.

No entanto, essas concepções do que seriam uma família estruturada, um modelo firme de masculino e feminino e natureza estão baseadas, única e exclusivamente, em ideias religiosas de um determinismo de gênero e de uma fixidez da sexualidade calcados na cisgeneridade ${ }^{4}$ e na heteronormatividade ${ }^{5}$ (Natividade, 2006). A homossexualidade, por não corres-

\footnotetext{
4 “[...] a cisnormatividade, ou normatividade cisgênera - que exerce, através de variados dispositivos de poder interseccionalmente situados, efeitos colonizatórios sobre corpos, existências, vivências, identidades e identificações de gênero que, de diversas formas e em diferentes graus, não estejam em conformidade com seus preceitos normativos” (Vergueiro, 2015, p. 43).

5 "A heteronormatividade visa regular e normatizar modos de ser e de viver os desejos corporais e a sexualidade De acordo com o que está socialmente estabelecido para as pessoas, numa perspectiva biologicista e determinista, há duas - e apenas duas - possibilidades de locação das pessoas quanto à anatomia sexual humana, ou seja, feminino/fêmea ou masculino/macho" (Petry, \& Meyer, 2011, p. 195).
} 
ponder a esse modelo, seria um desvio produzido por falhas no desenvolvimento infantil. Logo, a Psicologia é convocada como uma forma de sanar as causas que geraram o suposto "estado homossexual". Curiosamente, a Psicologia é convocada para que valores religiosos específicos sejam afirmados. Sendo assim, é possível afirmar nitidamente uma falha ética, justamente porque a Psicologia, como ciência e profissão, é laica, e não se presta a afirmar valores morais. Entretanto, ela deve questionar as condições e discursos que produzem ou impossibilitam a existência plural das subjetividades (Bicalho, Cassal, Magalhães, \& Geraldini, 2009).

As práticas que tentam reverter as orientações homossexuais se configuram como práticas de tortura por violarem direitos humanos, gerarem danos físicos e psíquicos e utilizarem de ameaça, força, constrangimento e violência. Temos um vislumbre dessa situação no contexto das Comunidades Terapêuticas que, em sua maioria, são evangélicas ou de motivação evangélica ou católica. Há evidências de tentativas de reorientação da homossexualidade, desconsideração da diversidade sexual, repressão da expressão das sexualidades, por vezes, associando homossexualidades e várias expressões de gênero à ideia de pecado (CFP], Ministério Público Federal [MPF], 2018). Além do mais, temos duas importantes biografias ${ }^{6}$ que retratam com riqueza de detalhes as várias formas de tratamento e sofrimento que dois jovens se submeteram ao tentarem reverter suas orientações homossexuais. Em Prayers for Bobby, Bobby passa por várias tentativas frustradas de reverter sua homossexualidade (Aarons, 1996). Ele se afasta da família por se sentir rejeitado e acaba por cometer suicídio. Em Boy Erased, o autor Garrard Conley (2019) narra sua própria história de tortura na participação de um grupo que pretendia reverter a sua homossexualidade, mas que, no processo, produz mais sofrimento e violência. Que prática poderia ser chamada de terapêutica se baseada em tortura, gerando mais sofrimento e dor e até mesmo o sui- cídio? Como a Psicologia, enquanto ciência e profissão, pode permitir essas práticas?

De fato, conforme elaboram Dunker e Kyrillos (2010), uma ação social estigmatizante e um contexto político preconceituoso sobre gênero e sexualidade produzem angústia em sujeitos que se percebem dissidentes à heteronormatividade, o que pode gerar vários efeitos psíquicos de sofrimento. Sawaia (1999) os afetos experimentados pela dor de habitar um espaço hostil a um determinado modo de existência caracterizou como "sofrimento ético-político". No entanto, alguns psicólogos com motivações religiosas propõem utilizar o DSM e o $\mathrm{CID}^{7}$ para justificar suas práticas, produzindo uma pseudociência em que a saída para esse sofrimento seria a modificação da orientação homossexual.

Além disso, o psicólogo cognitivista espanhol, Jiménez Díaz (2012), pesquisou pessoas que apresentam desconforto com suas orientações homossexuais e constatou que toda tentativa de reversão da homossexualidade gerava efeitos iatrogênicos em seus pacientes. Por isso, é dever da Psicologia promover uma análise sobre os contextos sociais e políticos que produzem sofrimento. A tentativa de modificação das orientações homossexuais só se sustentaria em contextos religiosos fundamentalistas que não se baseiam na produção ética, laica e científica da Psicologia ${ }^{8}$.

O exercício profissional irregular em Psicologia não pode ser justificado por mera discordância com as normas vigentes: elas deveriam ser disputadas politicamente através dos processos democráticos do Sistema Conselhos de Psicologia (definição de prioridades no Congresso Nacional da Psicologia) e embasadas técnica e cientificamente através de pesquisa teórica e experimental, esta regulada pelas resoluções de ética em pesquisa com seres humanos - no 466/2012 e no 510/2014 do Conselho Nacional de Saúde. Dessa feita, a Resolução no 1(1999) se mostra eficiente na manutenção da ética e da ciência psicológicas por proibir práticas de tortura com motivações religiosas. Em outras palavras, estas práticas

\footnotetext{
${ }^{6}$ As biografias são Prayers for Bobby: A Mother's Coming to Terms with the Suicide of Her Gay Son, de Leroy F. Aarons, publicada nos Estados Unidos em 1996, e Boy Erased - Uma verdade anulada, escritaopor Garrard Conley e publicadaono Brasil pela editora Intrínseca, no ano de 2019.

${ }^{7}$ Vale destacar que o DSM III (de 1987) e o CID 11 (de 2018) retiraram a "orientação sexual egodistônica" da lista de categorias patológicas.

${ }^{8}$ Após a escrita deste artigo, foi publicado o livro Tentativas de aniquilamento de subjetividades LGBTI, organizado pela Comissão de Direitos Humanos do Conselho Federal de Psicologia, que reitera nosso argumento com a apresentação de relatos de pessoas LGBTI que foram submetidas às práticas de reversão e o sofrimento decorrente das mesmas. Conferir: htts://site.cfp.org.br/publicacao/tentativas-de-aniquilamento-de-subjetividades-lgbtis/, consultado em 10, setembro, 2019.
} 
não apresentam embasamento teórico psicológico; portanto, não podem ser enquadradas como parte deste exercício profissional. E, além disso, produzem efeitos que violam direitos humanos, gerando sofrimento e adoecimento psíquico, ferindo a possibilidade de uma ética profissional comprometida com a produção de saúde.

\section{Patologização e diretrizes éticas}

As práticas que tentam reverter a homossexualidade são formas de patologização de experiências sexuais, e por isso, propõem-se como suposta cura. Ora, na medida em que as orientações sexuais não heteronormativas não são doença, desvio ou perversão, conforme determina a Resolução no 1(1999), a Psicologia não pode oferecer práticas profissionais de suposta cura ou reversão.

Mas a Resolução não trata exclusivamente de proibições. $\mathrm{O}$ seu artigo $2^{\circ}$ orienta profissionais a enfrentarem preconceito, discriminação e estigmatização contra práticas homoeróticas. Nesse sentido, é uma diretriz ética que pessoas psicólogas devem incorporar em seu exercício profissional, em quaisquer áreas e públicos. Isso significa que falas e textos produzidos por psicólogas e psicólogos, em seu exercício profissional, precisam criticar a patologização da homossexualidade (e de quaisquer orientações sexuais que destoam da heteronormatividade).

É importante destacar que as práticas de tortura analisadas anteriormente estão fundadas em uma busca por uma suposta verdade individual, estabelecida no desejo sexual, a ser confessada, revelada e modificada (Foucault, 1987). Entretanto, essa não é a única estratégia de patologização. De fato, outra leitura essencializante da homossexualidade é entendê-la como defeito imutável e, por isso, as práticas dirigidas à sua transformação seriam simplesmente desnecessárias. Essa posição não abandona a perspectiva patologizante; pelo contrário, pode-se interpretar a homossexualidade como experiência essencialmente patológica, contagiante e de ameaça social. Nesse sentido, as pessoas percebidas como homossexuais deveriam ser simplesmente excluídas de espaços e relações públicas - ou mesmo eliminadas. Saímos, então, do campo da simples proibição de práticas que tentam reverter a homossexualidade para um território delicado de exercícios profissionais da Psicologia que podem, ou não, produzir e reproduzir patologizações.
Uma das demandas recorrentes ao exercício da Psicologia Escolar, por exemplo, é nomeada de indisciplina (Aquino, 1998; Patto, 1981). São práticas disruptivas de estudantes nos diferentes espaços e processos da escola, a romper com a estrutura fundamental que permeia a instituição escolar moderna - a disciplina, também chamada de poder disciplinar (Foucault, 1987). Em tais contextos, a Psicologia Escolar é convocada para adequar os comportamentos de pessoas e grupos, de forma a fazê-los atender às regras esperadas de funcionamento; em outras palavras, a assujeitá-los para que a instituição funcione com o mínimo de ruído possível. Por outro lado, uma prática crítica de Psicologia Escolar coloca em análise a que interesses as regras atendem e como construir processos comprometidos com a coletividade, a democracia e a aprendizagem significativa no ambiente da escola (Aquino, 1998; Patto, 1981). Há tensões e disputas entre os fazeres da Psicologia Escolar no campo das teorias e técnicas, mas todas essas práticas são possíveis enquanto parte de um campo do exercício profissional (Melsert, \& Bicalho, 2012).

O que se nomeia indisciplina está relacionado a regras de delimitação e controle do tempo, do espaço, das funções do espaço, dos comportamentos e das expressões do corpo, da higiene, da modéstia, entre outros (Foucault, 1988). A sexualidade permeia estas regras, no sentido de proibições de relações, expressões e discursos no espaço escolar. Além disso, a expressão de gênero é usada como critério para supor uma verdade sobre orientações sexuais - nesse sentido, "parecer" (ser socialmente interpretado) como uma pessoa homossexual seria tão grave quanto "assumi-lo" como identidade (Cassal, \& Bicalho, 2011). É a produção de silêncios como exercícios de poder na instituição de escolar, na tentativa de que corpos e relações operem de acordo com as normas (Ferrari, \& Marques, 2011).

A heteronormatividade é tomada como referência para o comportamento no ambiente escolar; as manifestações desviantes são entendidas como violações às normas de modéstia e expressão e, portanto, indisciplina. A homossexualidade, como fato ou suposição no ambiente escolar, pode ser lida como manifestação de indisciplina: em nome da ordem do espaço escolar, que seria perturbado por quaisquer expressões e manifestações dissidentes à heteronormatividade (seja manifestações de afeto 
por adolescentes do mesmo gênero ou expressões de gênero fora do enquadramento binário, estável e dicotômico). "A produção desta condição de bom aluno não se resume às exigências explícitas de regulamentos escolares oficiais, mas às expectativas constituídas em torno de seus corpos por múltiplos discursos em que gênero e sexualidade se atravessam" (Ranniery, 2017, p. 16).

Ora, se a indisciplina é problema da Psicologia, então também o seria a demanda pela correção de expressões entendidas socialmente como de pessoas homossexuais. Não mais por se tratar de algo a ser revertido, mas em discursos fundados no medo (adulto) da possibilidade de identificação ou assunção de uma suposta futura homossexualidade por crianças e adolescentes (Cassal, 2017; Cornejo, 2011; Sedgwick, 1991).

A Psicologia Escolar, nesse sentido, poderia disciplinar: reprimir manifestações de afeto, desqualificar declarações de identidade ou expressões de gênero. No instável e interminável campo da ética profissional, temos um problema a ser analisado afinal, não seriam posicionamentos que associam comportamentos de gênero à homossexualidade e esta, como uma experiência patológica ou, ao menos, indevida? Não se trataria de cura; mesmo assim, isso estaria auxiliando ou enfrentando a discriminação e a patologização?

As políticas de saúde sexual são outro campo de intervenção da Psicologia com interface com as discussões sobre homossexualidade. As práticas sexuais são de imenso interesse para o biopoder, por cruzarem a disciplina individual, a geração de descendentes e a regulação da população (Foucault, 1988); dessa maneira, regular a homossexualidade através de normativas legais ou da gestão do medo tem efeitos diretos de poder (Cassal, 2013). O estabelecimento de identidades é fundamental para a reivindicação de direitos frente ao Estado, mas também cria pontos de suporte para estigmatizações institucionais: "A produção de subjetividades identitárias atua na construção da sexualidade como um vetor que atravessa e constitui essas vulnerabilizações" (Cassal, Garcia, \& Bicalho, 2011, p. 471).

A identificação de práticas sexuais é usada em diversos países, inclusive no Brasil, como critério para a doação de sangue, regulada pela Portaria do Ministério da Saúde (MS) no 158/2016, que exige ao doador a abstinência de práticas sexuais entre homens por 12 meses:

[A] política de restrições à doação de sangue por HSHs[Homens que fazem Sexo com Homens] foi adotada mundialmente como uma resposta à crise da AIDS, que atingiu especialmente a comunidade homossexual masculina. Embora pudesse ter parecido razoável em outro contexto histórico, a mesma vem sofrendo muitos questionamentos por parte da comunidade científica, que alega que a mesma não mais se sustenta diante do desenvolvimento científico, e de juristas e ativistas, que destacam os efeitos deletérios que a mesma gera para os direitos e a identidade de homens homossexuais (Cardinali, 2017, p. 132).

Assumir como pressuposto que homens que fazem sexo com homens estão mais propensos à contaminação com HIV/AIDS/IST não significa necessariamente associar homossexualidade com enfermidade psíquica, mas a patologização também reverbera em outras dimensões da existência. Mais uma vez, entramos no campo da diretriz ética: como a Psicologia pode operar nos serviços de saúde para criticar a associação entre orientações sexuais e HIV/AIDS/IST: "a restrição se baseia em concepções científicas ultrapassadas que acabam por reforçar estereótipos negativos que relacionam homossexualidade a 'promiscuidade' e 'perigo', atuando na perpetuação de estigmas” (Cardinali, 2017 p. 132). Dessa forma, temos uma normativa legal estigmatizante sobre a doação de sangue e, por outro, uma resolução profissional de enfrentamento à patologização da homossexualidade. Não se trata aqui de descumprir regulamentações, mas buscar direções éticas para o exercício profissional. No ambiente clínico e nas instituições de saúde, profissionais de Psicologia podem questionar tanto as certezas patologizantes quanto os sofrimentos produzidos em função de tal proibição. Isso é feito através da contextualização histórica e social.

A Psicologia baseia-se em princípios técnicos e científicos. Na medida em que não há embasamento para a discriminação na doação de sangue, a Resolução no 1 (1999) regulamenta que os discursos públicos da Psicologia não devem corroborar com esta estigmatização e, além disso, profissionais devem se posi- 
cionar pela mudança de legislação, especialmente através da produção de conhecimento científico e dos espaços de controle social (Conselhos e Conferências de Saúde e de Direitos Humanos). Isso não significa desrespeitar a legislação vigente, mas apontar um caminho ético possível quando um documento estatal viola direitos recorrentemente.

Um terceiro espaço de intervenção está diretamente implicado ao campo da Psicologia jurídica. A adoção de crianças e adolescentes por casais de pessoas do mesmo gênero não possui legislação própria, mas já é autorizada através de decisões de jurisprudência, inclusive pela decisão do STF em 2013 sobre a equiparação da união estável de pessoas do mesmo gênero ao casamento.

Nos processos de habilitação para adoção, [...] não era comum que casais homoconjugais entrassem com o pleito em conjunto. Apenas um dos cônjuges costumava figurar como postulante, em que pese ser um projeto homoparental do casal, não um projeto monoparental. No percurso da pesquisa, pude observar que essa realidade tem se transformado com muita rapidez. [...] Os efeitos da decisão do STF em 2011, concernente as homoconjugalidades, ao que parece, fora pacifica a partir do momento em que o Supremo negou provimento ao recurso perpetrado pelo Ministério Público estadual do Paraná em processo de habilitação para adoção de um casal de homens (Daros, 2016, p.43-44).

A Psicologia é especialmente estratégica no enfrentamento à estigmatização por orientação sexual na questão da adoção. Além de sermos profissionais que produzem parecer para sustentar as decisões judiciais, a regulamentação da profissão também tem sua função. Nesse sentido, a Resolução no 1(1999) já foi utilizada como fundamentação de que a homossexualidade não é patologia e, portanto, não oferece prejuízo ou risco à criança.

Parece, então, que a dificuldade da sociedade jurídica brasileira está em aceitar a existência de famílias homoafetivas [...], na cidade de Catanduva-SP, em 2004, quando o juiz e o promotor, dentre outros fundamentos para a aceitação da adoção conjunta, orientaram-se pela Resolução $n^{\circ}$ 01/99, do Conselho Federal de Psicologia, que, estabelecendo normas de atuação para os psicólogos em relação à orientação sexual humana, veda qualquer tipo de tratamento discriminatório com relação à homossexualidade, ratificando que esta não se trata de doença, desvio ou distorção (Castro, 2008, p. 23).

A Psicologia Jurídica participa da garantia de direitos, tendo como objetivo a proteção dos sujeitos envolvidos. No caso da adoção, deve considerar a condição especial de crianças e adolescentes e atuar em seu interesse superior. Assim, profissionais de Psicologia realizam um processo avaliativo das condições para habilitar as famílias à adoção. Ora, proteger, de fato, será através de uma atuação técnica fundamentada. Nesse sentido, tomar gênero e orientação sexual das pessoas pleiteantes à adoção como características que permitem ou não a habilitação seria incorrer em uma prática arbitrária e, portanto, ética e tecnicamente frágil.

A compreensão de que uma família homoconjugal para o exercício parental seria inadequada, não parece estar vinculada apenas a questão do processo identificatório, mas em decorrência, também ao preconceito em relação à população LGBTTIQ [sic], chegando alguns, como se sabe, a identificar as homossexualidades com a pedofilia (Daros, 2016, p. 132).

O preconceito socialmente estabelecido leva a associação da homossexualidade a condições patológicas. Se anteriormente discutimos a aproximação equivocada com HIV/AIDS/IST, agora seria com a pedofilia. Mais uma vez, a homossexualidade não é discutida como uma patologia em si, mas a expressão de uma condição de adoecimento e que, por isso, precisaria ser retirada de circulação.

O discurso de associação da pedofilia à homossexualidade chega ao absurdo de se nomear a pedofilia como uma orientação sexual, apenas para um falso argumento que indique uma condição patológica das experiências não heteronormativas. Esse discurso sustenta e produz discriminações e preconceitos, inclusive em situações de trabalho (como a ideia de que pessoas homossexuais ou bissexuais não poderiam trabalhar com crianças, especialmente em profissões de cuidado) e de família (com o afastamento 
de pessoas homossexuais ou bissexuais de relacionamento com parentes crianças).

Como Daros (2016) argumenta, é necessário que a Psicologia Jurídica não tome a heteronormatividade como modelo universal tanto de família como de proteção à infância. Quando o exercício profissional rompe com a estigmatização e habilita a composição de famílias com pessoas do mesmo gênero, expressa que tais modos de existência são legítimos. Com isso, amplia as possibilidades de família na realidade, mas também na imaginação.

De fato, a Resolução no 1(1999), para além de proibir, promove o reconhecimento da orientação sexual como característica humana legítima. É mais do que vetar as práticas de conversão por falta de eficácia e fundamentação. O exercício profissional comprometido com essa diretriz ética é capaz de reduzir a discriminação e estigmatização, pois cria possibilidades em que as homossexualidades são possíveis de serem vividas, exercidas, inventadas. Com isso, mais histórias podem ser contadas, para além (espera-se) de um registro heteronormativo.

\section{Dos efeitos de subjetivação e criminalização}

Em fevereiro de 2019, o STF iniciou a votação de duas ações ${ }^{9}$ que solicitam a criminalização da LGBTIfobia e sua equiparação criminal ao racismo. Os votos já declarados foram favoráveis, e há uma grande mobilização dos movimentos sociais LGBTI (pessoas lésbicas, gays, bissexuais, travestis, transexuais e intersexo) em defesa da criminalização ${ }^{10}$. Entretanto, também surgiram diversas vozes dissonantes nestes mesmos movimentos, apontando críticas tanto em termos de estratégia (através do judiciário), de mérito (sobre a equiparação) e mesmo de fundamentos (crítica ao Estado Penal). Trata-se, então, de uma disputa das estratégias de enfrentamento à violência. O CFP manifestou-se favoravelmente às ações e foi convidado a participar na sustentação oral em defesa das mesmas ${ }^{11}$.

Criminalização, para além da definição de um tipo penal, é um processo de estabelecimento de uma norma, que regulamenta ações e comportamentos, sendo possível de ser transgredida e, nesse caso, prevendo punição ao infrator (Bicalho, 2005; Dornelles, 1988; Rauter, 2003;). Esse processo punitivo está fundado em um poder disciplinar (Foucault, 1987), que localiza os comportamentos em corpos individualizados, nos quais se deve intervir para corrigir. Isso é aqui compreendido na perspectiva de processos de subjetivação (Guattari, \& Rolnik, 1996), em que os modos de sentir, pensar, comunicar e relacionar são produzidos em relações históricas e sociais entre saber, poder, linguagem e materialidade.

Ora, as práticas e procedimentos que a Resolução CFP no 1(1999) estabelece como estranhas à Psicologia são aquelas que se dirigem para a patologização e eliminação de modos de existência LGBTI. A Resolução estabelece as normas de funcionamento da profissão e, na medida em que há transgressões, pune os infratores. Podemos entender, portanto, que este documento, desde 1999, opera um processo de criminalização da LGBTIfobia - evidentemente, em um campo específico.

Em uma perspectiva que compreenda os processos de subjetivação, a criminalização pode reduzir certos comportamentos e práticas na medida em que estabelece uma futura punição a ser temida pelos indivíduos, além de indicar a deslegitimação social e estigmatização de certas práticas como infrações. Dessa forma, o exercício irregular feito por práticas e procedimentos de reversão da sexualidade por profissionais de Psicologia é um posicionamento em relação a uma criminalização. Não pretendemos, aqui, compreender todas as razões para esse ato, mas perceber que a ameaça de punição e a ilegitimidade profissional de tais práticas são insuficientes para impedi-las em totalidade (Cassal, 2013).

O que a Resolução no 1(1999) busca enfrentar é o regime de verdade que torna legítimo ou, ao menos, aceitável a violência (discursiva, física e institucional) contra população LGBTI, a ponto de este ser, hoje, um fato recorrente e corriqueiro. Desse modo, enquanto Psicologia, discursos e falas de des-

\footnotetext{
${ }^{9}$ Ação Direta de Inconstitucionalidade por Omissão no 26 e Mandado de Injunção no 4733.

${ }^{10}$ Essa era o estado da arte quando da escrita deste artigo. O STF julgou favoravelmente a criminalização (por oito votos a três) em 13 de junho de 2019. Conferir: https://www.bbc.com/portuguese/brasil-47206924, recuperado em 10, setembro, 2019.

${ }^{11}$ Conferir: https://observatoriog.bol.uol.com.br/entrevistas/2019/02/paulo-iotti-fala-sobre-a-criminalizacao-da-homofobia-no-stf, recuperado em 28, abril, 2019.
} 
truição não pertencem ao nosso campo legítimo de exercício profissional.

Da mesma maneira, a criminalização julgada no STF espera reduzir as transgressões (crimes de ódio) em função da expectativa da punição criminal e a estigmatização desta infração (na medida em que está institucionalmente estabelecida como proibida). De fato, as ações no Supremo usam tal argumento em sua defesa ${ }^{12}$.

Não há garantias para os processos de subjetivação: na realidade, nenhuma regulamentação pode dar conta das possibilidades de experiência e expressão humana. Mais ainda, o poder não subtrai, mas produz e multiplica efeitos. A proibição de um ato ou exercício produz relações e posições dos sujeitos, infratores ou não. Como indica Butler (2017, p. 19), "O poder jurídico 'produz' inevitavelmente o que alega meramente representar; consequentemente, a política tem de ser preocupar com essa função dual do poder: jurídica e produtiva”. Dessa maneira, as legislações devem servir menos para restringir, e mais para criar condições para mundos em que as vidas sejam mais vivíveis (Butler, 2016), o que inclui que todas sejam reconhecidas como legítimas, sendo defendidas e lamentadas.

Para além da produção de criminalizações, é preciso evidenciar o que se quer construir como tempo presente. A Resolução no 1(1999) é bastante discutida no que proíbe; entretanto, precisamos evidenciar também a direção que exige: produção de conhecimento científico e exercício profissional que enfrentam a discriminação e a desigualdade. Como discutimos anteriormente em relação aos desafios cotidianos de campos específicos de atuação, há direções éticas a nos posicionarmos. Esse é, talvez, um ponto da Resolução a ser cada vez mais valorizado, para reconhecer como legítimas as vidas e existências das populações LGBTI (Cassal, 2014).

Nesse sentido, reforçamos o que já é discutido, de forma majoritária, pelos movimentos LGBTI, apesar das divergências sobre a criminalização como solução: o julgamento favorável pelo STF não será o fim de todos os problemas. Será necessário posicionar-se de maneira crítica à violência e discriminação, bem como reduzir a vulnerabilidade da população LGBTI. Para isso, é necessário instituir e executar, de forma permanente, políticas públicas especializadas nos campos de segurança pública, saúde, educação, trabalho e assistência social, dentre outros, com participação direta da sociedade civil em sua fiscalização e monitoramento, especialmente através dos conselhos de direitos ${ }^{13}$.

Ao mesmo tempo, as diferenças precisam aparecer enquanto parte constitutiva de nós e nossa sociedade. Isso implica no reconhecimento do processo histórico de perseguição e destruição da população LGBTI através da violência, da invisibilização e da patologização oficial no século XX. Isso significa o reconhecimento das narrativas apagadas e destruídas em nosso processo histórico e a valorização das estéticas, relações e possibilidades silenciadas. Essa reconstrução da nossa história e da nossa memória, enquanto uma sociedade estruturalmente LGBTIfóbica (além de racista, classista, machista, cissexista, capacitista), mas que luta para não mais o sê-lo, é um esforço que pode mudar a subjetivação sobre as experiências dissidentes de gênero e sexualidade.

Especificamente na Psicologia, esse modo de operar implica na produção de conhecimento, discursos públicos e práticas profissionais de forma que a diversidade sexual e de gênero sejam percebidas como parte das inúmeras possibilidades do viver. Corpos e expressões tidas como estranhas pelas normas sociais (Louro, 2004), mas estranheza que não configura crime ou doença, e sim uma posição social e historicamente constituída. A Psicologia, como ciência e profissão dedicada à subjetividade humana, tem um papel estratégico para reforçar esse entendimento, enquanto categoria e para toda sociedade. A discussão dos direitos LGBTI não pode ser furtar aos procedimentos e práticas de reorientação sexual, mas também não pode se limitar a ela. O enfrentamento à LGBTIfobia, de forma estrutural, precisa se dar em muitos planos.

A criminalização é uma estratégia ardilosa, com a qual devemos ter extrema atenção. No caso da Resolução no 1(1999), ela tornou-se alvo de diversos ques-

\footnotetext{
${ }^{12}$ http://www.academia.edu/10150058/Mandado_de_Injun\%C3\%A7\%C3\%A3o_MI_4733, recuperado em 23, abril, 2019. Ainda que discordemos da expressão "inconsciente coletivo social” utilizada, que não remete especificamente a nenhuma tradição da Psicologia a interpretação do mandado de injunção parece aproximada às compreensões de processos de subjetivação a partir de Guattari e Rolnik (1996) e a discussão de Foucault (1987) sobre os efeitos sociais das normas.

${ }^{13}$ Nesse sentido, concordamos com o CFP no repúdio à extinção de centenas de colegiados públicos pelo Governo Federal através do Decreto no 9.759/2019. Conferir: https://www.facebook.com/conselhofederaldepsicologia/videos/339523260082780/, recuperado em 21, abril, 2019.
} 
tionamentos jurídicos e legislativos, exigindo enorme esforço do CFP em sua manutenção. Por um lado, isso indica o posicionamento conservador de diversos setores, que defendem uma Psicologia em discordância tanto com o conhecimento científico quanto com os direitos humanos: uma batalha entristecedora. Por outro, esses momentos foram transformados em oportunidades, pelo Sistema Conselhos de Psicologia, para dar imensa visibilidade ao posicionamento ético e político da Psicologia, como ciência e profissão, em defesa dos direitos da população LGBTI, fomentando o debate e enfraquecendo as restrições sociais sobre gênero e sexualidade.

Durante o julgamento no STF, grande parte do movimento LGBTI defendeu a criminalização como solução. Chama atenção, entretanto, que o deputado federal Marco Feliciano ${ }^{14}$ tenha anunciado, em abril, que a bancada evangélica está a preparar um projeto de criminalização da "homofobia" [sic $]^{15}$. Políticos fundamentalistas religiosos, aliados à extrema-direita, estão interessados em disputar esse dispositivo legal. Talvez isso indique que a criminalização, por si só, não basta: esta pode ser distorcida até atender os interesses de grupos que historicamente se posicionaram contrários aos direitos da população LGBTI.

Afinal, por que a bancada evangélica interessar-se-ia em produzir e aprovar um projeto com tal temática? Algumas hipóteses cabem em nossa análise. A criminalização implica na delimitação do que são a norma e a transgressão. Ora, por exclusão, isso também define quais comportamentos e atos são permitidos. Assim, talvez esse grupo político tenha interesse em estabelecer sua própria definição de infração e, com isso, eliminar da regulação aqueles exercícios que lhes interessem. É possível, portanto, que a definição a ser estabelecida não seja a mesma proposta pelas ações no STF e pautadas pelos movimentos LGBTI. Ao mesmo tempo, isso cria uma aparência de flexibilidade para um grupo tomado como conservador, podendo inclusive servir para o fortalecimento de grupos e parlamentares atualmente intitulados como "gays de direita" e ligados a movimentos conservadores. Além disso, a criminalização da LGBTIfobia tem como efeito colateral a expansão de uma política de segurança pública fundada no delito e no encarceramento, sendo que o sistema carcerário brasileiro apresenta inúmeras irregularidades e violações de direitos humanos (Bicalho, 2016; Reishoffer, \& Bicalho, 2015). De fato, esta é uma das fortes críticas apresentadas por parte dos movimentos LGBTI a qualquer decisão pela criminalização.

Vale destacar que o fortalecimento de um estado policial, o acirramento da violência e a resolução de conflitos através de encarceramento são de especial interesse dos movimentos de extrema-direita em variados níveis de governo no Brasil. De fato, grupos conservadores parecem convidar parte dos movimentos e da população LGBTI para um processo chamado por Jasmine Puar de "homonacionalismo" (2007). De acordo com a autora, o Estado neoliberal constrói políticas que promovem direitos da população LGBTI, mas o fazem de forma a ignorar ou mesmo alimentar políticas nacionalistas racistas e xenófobas. Talvez, em alguma medida, a "criminalização da homofobia" de Marco Feliciano, ao ser elaborada por grupos conservadores e da extrema-direita, tenha a mesma função de aumentar as desigualdades sociais de classe, gênero, raça, religião e origem geográfica em uma aparente legislação progressista.

\section{Desafios atuais e algumas considerações}

Os segmentos da sociedade brasileira que advogam pela manutenção dos padrões heteronormativos têm atuado no sentido de sustar e retirar os marcos legais e jurídicos que garantiram os avanços de direitos e cidadania da população LGBT, entre eles a Resolução CFP no 1(1999).

Tais segmentos, que defendem que a homossexualidade deve ser tratada como patologia ou desvio, alicerçam-se em concepções que remontam a amálgamas de visões fundamentalistas de algumas vertentes religiosas, ou ainda versões (também) fundamentalistas da ciência médica e psicológica, além de perspectivas conservadoras das relações sociais. São posturas calcadas numa lógica de naturalização da heterossexualidade como padrão e regra a ser seguida, visando garantir um projeto de sociedade que diminua o espaço de cidadania e direitos para

\footnotetext{
${ }^{14} \mathrm{O}$ político, filiado ao Podemos-SP e membro da bancada evangélica do congresso nacional, assumiu publicamente diversas posições contrárias aos direitos LGBTI ao longo dos anos.

${ }^{15}$ Conferir: http://ultimosegundo.ig.com.br/politica/2019-04-24/bancada-evangelica-vai-apresentar-projeto-que-criminaliza-a-homofobia-no-brasil.html, recuperado em 01, maio, 2019.
} 
pessoas que vivenciam diversidades de expressões de gênero e orientação sexual.

Entende-se que a LGBTIfobia é um processo de estigmatização que incorre em violação de direitos, como efeito de representações de inferiorização, patologização e mesmo desumanização que recaem sobre sujeitos cuja orientação sexual e expressão de gênero não estão em conformidade com os estereótipos da cis-heteronormatividade (Petry \& Meyer, 2011; Vergueiro, 2015). Desta forma, não é a condição existencial de ser LGBTI que gera o sofrimento, mas sim as vivências de exclusão e marginalização causadas pela discriminação.

As violências lesbofóbica, homofóbica, bifóbica, travestifóbica, transfóbica e intersexofóbica no Brasil se manifestam nos diversos espaços sociais - intrafamiliar, escolar, religioso e laboral - por meio de estigmatizações, evasão escolar, rejeição social e familiar, perda de vínculos nos espaços religiosos, dificuldade de acesso e permanência no mercado de trabalho.

A construção sociocultural da LGBTIfobia e suas expressões violentas são fenômenos complexos, contra o qual o envolvimento e a prática da Psicologia pode (e deve) contribuir para sua diminuição. Deverão, a psicóloga e o psicólogo, ter como princípio o respeito à livre orientação sexual dos indivíduos, além de apoiar a elaboração de formas de enfrentamento no lidar com as realidades sociais de maneira integrada. Isso porque a questão da orientação sexual, como expressão do direito humano, distancia-se radicalmente de conceitos de cura e doença, desvio e reorientação.

A despatologização é a reparação de um grave erro histórico, que produziu estigmatização, sofrimento e violência. A Resolução no 1(1999) corrobora, de fato, com tal sentido político. Esta Resolução, já nacional e internacionalmente reconhecida, pode vir a sofrer alguma restrição por instituições exteriores ao Sistema Conselhos, como houve anteriormente. Entretanto, a experiência da Psicologia em nome da despatologização das orientações sexuais está marcada nas e nos profissionais, na produção de conhecimento e na sociedade. Além disso, o Código de Ética Profissional defende os direitos humanos de forma geral e, especificamente, veta que profissionais induzam convicções de orientação sexual, no que podemos entender as práticas de tentativa de reversão da homossexualidade. Isso porque a Psicologia brasileira tem histórias e memórias de décadas de lutas.

Em 1999, a proibição de práticas e procedimentos de reorientação sexual (ou, como argumentamos aqui, a criminalização da LGBTIfobia na Psicologia) foi avaliada como necessária e estratégica. Vinte anos depois, percebemos que ela foi e continua importante e objeto de disputa, mas também reconhecemos que é insuficiente. Isso precisa estar no horizonte das discussões em torno da criminalização da LGBTIfobia pelo STF. Caso a decisão seja favorável, ainda há muito por fazer, inclusive por novos problemas que surgirão em função disso. Em caso negativo, nem tudo está perdido, pois há diversas outras frentes fundamentais dessa disputa. De todo modo, qualquer que seja a decisão, será um momento histórico pelo tamanho e visibilidade alcançados neste debate. Afinal, a Resolução no 1(1999) é o marco de um projeto ético e político a ser defendido, do que queremos para a Psicologia: rigor técnico, fundamentação científica, impacto social e garantia de direitos.

\section{Referências}

Aarons, L. F. (1996). Prayers for Bobby: A mother's coming to terms with the suicide of her gay son. San Francisco: Harperone.

Aquino, J. G. (1998). A indisciplina e a escola atual. Revista da Faculdade de Educação, 24(2), 181-204. https://doi. org/10.1590/S0102-25551998000200011

Bicalho, P. P. G. (2005). Subjetividade e abordagem policial: por uma concepção de direitos humanos onde caibam mais humanos (Tese de doutorado). Instituto de Psicologia, Universidade Federal do Rio de Janeiro, Rio de Janeiro, RJ, Brasil.

Bicalho, P. P. G. (2016). A formação do Psicólogo e a Violação de direitos na custódia de presos no Brasil. In: D. P. Celis, N. Zicavo, \& M. Calviño (Orgs.), El hacer y el pensar de la Psicología CON América Latina (pp. 87-97). Santa Marta: Alfepsi,.

Bicalho, P. P. G., Cassal, L. C. B., Magalhães, K. C., \& Geraldini, J. R. (2009). Formação em psicologia, direitos humanos e compromisso social: A produção micropolítica de novos sentidos. Boletim Interfaces da Psicologia, 2(2), pp. 20-35. 
Psicologia: Ciência e Profissão 2019 v. 39 (n.spe 3.), e228516,113-128.

Butler, J. (2016). Corpos que ainda importam. In: L. Colling (Org.), Dissidências sexuais e de gênero (pp.19-42). Salvador, BA: EDUFBA.

Butler, J. (2017). Problemas de gênero: Feminismo e subversão da identidade (13a ed.). Rio de Janeiro, RJ: Civilização Brasileira.

Cardinali, D. (2017). A proibição de doação de sangue por homens homossexuais: uma análise sob as teorias do reconhecimento de Fraser e Honneth. Revista Digital Constituição e Garantia de Direitos, 9(2), 110 -136.

Cassal, L. C. B. (2013). Homofobia e cidade: Um ensaio sobre lâmpadas, segurança e medo. Polis e Psique, 3(3), 24-38. https://doi.org/ 10.22456/2238-152X.42294

Cassal, L. C. B. (2014). Psicologia e homofobia: Uma cartografia de encontros, embates e políticas. In: Conselho Regional de Psicologia do Rio de Janeiro (Org.), Experiências em Psicologia e políticas públicas (pp. 29-42). Rio de Janeiro, RJ: o autor.

Cassal, L. C. B. (2017). Medo de quê? Narrativas sobre homofobia e heteronormatividade na escola. In: E. Macedo, \& T. Ranniery. (Org.). Currículo, sexualidade e ação docente (pp. 107-130). Petrópolis, RJ: DP et alii.

Cassal, L. C. B., \& Bicalho, P. P. G. (2011). "Não importa ser ou não ser, importa parecer”: Pistas sobre violência homofóbica e educação. In: A. Bortolini (Org.), Diversidade sexual e de gênero na escola: Educação, cultura, violência e ética (pp.78-93). Rio de Janeiro, RJ: Pró-Reitoria de Extensão/UFRJ.

Cassal, L. C. B., Garcia, A. M., \& Bicalho, P. P. G. (2011). Psicologia e o dispositivo da sexualidade: Biopolítica, identidades e processos de criminalização. Psico, 42(4), pp. 465-473.

Castro, M. C. D. (2008). A adoção em famílias homoafetivas. In: Conselho Federal de Psicologia - CFP. (Org.), Adoção: $u$ m direito de todos e todas (pp. 23-26). Brasília, DF: o autor

Cavalcanti, C., Carvalho, M. W. V., \& Bicalho, P. P. G. (2018). A estranha liberdade de odiar: Uma análise do processo de Ação Civil Pública contra a resolução 01/2018 do Conselho Federal de Psicologia. Periódicus, 1(10), $231-249$. https://doi.org/10.9771/peri.v1i10.27943

Conley, G. (2019). Boy erased: Uma verdade anulada. Rio de Janeiro, RJ: Intrínseca.

Conselho Federal de Psicologia - CFP. (2005). Código de ética profissional do psicólogo: agosto 2005. Brasília, DF: o autor. Recuperado de https://site.cfp.org.br/wp-content/uploads/2012/07/codigo-de-etica-psicologia.pdf

Conselho Federal de Psicologia (s.d.). Sistema Conselhos. Brasília, DF: o autor. Recuperado de https://site.cfp.org. $\mathrm{br} / \mathrm{cfp} /$ sistema-conselhos/

Conselho Federal de Psicologia - CFP, \& Ministério Público Federal - MPF. (2018). Relatório da inspeção nacional em comunidades terapêuticas - 2017. Brasília, DF: os autores. Recuperado de http://www.mpf.mp.br/ atuacao-tematica/pfdc/midiateca/nossas-publicacoes/relatorio-da-inspecao-nacional-em-comunidades-terapeuticas-2017

Cornejo, G. (2011). La guerra declarada contra el niño afeminado: Una autoetnografía “queer”. Íconos: Revista de Ciencias Sociales, (39), 79-95.

Daros, L. E. S. (2016). Adoção judicial de filh@s por casais homossexuais: A heteronormatividade em questão (Tese de doutorado). Programa de Pos-Graduacao em Politicas Publicas e Formacao Humana, Universidade do Estado do Rio de Janeiro, Rio de Janeiro, RJ, Brasil.

Dornelles, J. R. (1988). O que é crime. São Paulo, SP: Brasiliense.

Dunker, C. I. L., \& Kyrillos, F., Neto. (2010). Curar a Homossexualidade?: A psicopatologia prática do DSM no Brasil. Revista Mal Estar e Subjetividade, 10,(2), 425-446.

Ferrari, A. M., \& Marques, L. P. (2011). Silêncios e educação. Juiz de Fora, MG: Universidade Federal de Juíz de Fora.

Foucault, M. (1979). Microfísica do poder. Rio de Janeiro, RJ: Graal.

Foucault, M. (1987). Vigiar e punir: Nascimento da prisão. Petrópolis, RJ: Vozes.

Foucault, M. (1988). História da sexualidade I: A vontade de saber. Rio de Janeiro, RJ: Graal.

Guattari, F., \& Rolnik, S. (1996). Micropolítica: Cartografias do desejo. Petrópolis, RJ: Vozes. 
Jiménez Díaz, R. (2012). La génesis de las parafilias sexuales y la homosexualidad egodistónica: El modelo de los mecanismos tensionales. Avances en Psicología Latinoamericana, 30(1), 146-158.

Lei No 5.766, de 20 de dezembro de 1971. Cria o Conselho Federal e os Conselhos Regionais de Psicologia e dá outros providências. Diário Oficial da União, 20 dez. 1971.

Louro, G. L. (2004). Um corpo estranho: Ensaios sobre sexualidade e teoria queer. Belo Horizonte, MG: Autêntica.

Melsert, A. L. M., \& Bicalho, P. P. G. (2012). Desencontros entre uma prática crítica em psicologia e concepções tradicionais em educação. Psicologia Escolar e Educacional, 16(1), 153-160. https://doi.org/10.1590/S141385572012000100016

Natividade, M. (2006). Homossexualidade, gênero e cura em perspectivas pastorais evangélicas. Revista Brasileira de Ciências Sociais, 21(61), pp. 115-132. https://doi.org/10.1590/S0102-69092006000200006

Passos, E., \& Barros, R. B. (2009). A cartografia como método de pesquisa-intervenção. In: R. B. Barros, V. Kastrup \& L. Escóssia. Pistas do método da cartografia: pesquisa-intervenção e produção de subjetividade (pp. 17-31). Porto Alegre, RS: Sulina.

Patto, M. H. S. (1981). Introdução à psicologia escolar. São Paulo, SP: T. A. Queiroz.

Petry, A. R., \& Meyer, D. E. E. (2011). Transexualidade e heteronormatividade: Algumas questões. Textos \& Contextos, 10(1), 193-198.

Projeto de Decreto Legislativo PDC 234. (2011). Susta a aplicação do parágrafo único do art. $3^{\circ}$ e o art. $4^{\circ}$, da Resolução do Conselho Federal de Psicologia no $1 / 99$ de 23 de Março de 1999, que estabelece normas de atuação para os psicólogos em relação à questão da orientação sexual. Recuperado de https://www.camara.leg.br/proposicoesWeb/fichadetramitacao?idProposicao $=505415$

Puar, J. (2007). Terrorism assemblages: Homonationalism in queer times. Durham: Duke University Press.

Ranniery, T. (2017). Currículo, normatividade e políticas de reconhecimento a partir de trajetórias escolares de 'meninos gays'. Education Policy Analysis Archives, 25(51), 1-32. https://doi.org/10.14507/epaa.25.2835

Rauter, C. (2003). Criminologia e subjetividade no Brasil. Rio de Janeiro, RJ: Revan.

Reishoffer, J. C., \& Bicalho, P. P. G. (2015). A circunscrição histórica das prisões e a crítica criminológica. In: F. R. Farias, \& L. S. Faceira. (Orgs.), Punição e prisão: Ensaios críticos (pp. 13-26). Rio de Janeiro, RJ: Lumen Juris.

Resolução CFP No 1, de 22 de março de 1999. Estabelece normas de atuação para os psicólogos em relação à questão da Orientação Sexual. Brasília, DF: CFP. Recuperado de https://site.cfp.org.br/wp-content/uploads/1999/03/ resolucao1999_1.pdf

Resolução CFP No 10, de 27 de março de 2018. Psicóloga e do Psicólogo e dá outras Dispõe sobre a inclusão do Nome Social na Carteira de Idendade Profissional da Psicóloga e do Psicólogo e dá outras providências. Brasília, DF: CFP. Recuperado de https://site.cfp.org.br/wp-content/uploads/2018/04/SEI_CFP-0037173-Resolu\%C3\%A7\%C3\%A3o.pdf

Resolução CFP No 14, de 20 de junho de 2011. Dispõe sobre a inclusão do nome social no campo "observação" da Carteira de Identidade Profissional do Psicólogo e dá outras providências. Brasília, DF: CFP. Recuperado de https://site.cfp.org.br/wp-content/uploads/2011/06/resolucao2011_014.pdf

Resolução CFP No 1, de 29 de janeiro de 2018. Estabelece normas de atuação para as psicólogas e os psicólogos em relação às pessoas transexuais e travestis. Brasília, DF: CFP. Recuperado de https://site.cfp.org.br/wp-content/ uploads/2018/01/Resolu\%C3\%A7\%C3\%A3o-CFP-01-2018.pdf

Rodrigues, S. (2018, 16 maio). Slogan "O Brasil voltou, 20 anos em 2" implora para ser interpretado como ato falho. Folha de São Paulo. Recuperado de https://wwwl.folha.uol.com.br/poder/2018/05/slogan-o-brasil-voltou-20-anos-em-2-implora-para-ser-interpretado-como-ato-falho.shtml

Sawaia, B. B. (1999). As artimanhas da exclusão: Uma análise ético-psicossocial da desigualdade. Petrópolis, RJ: Vozes.

Sedgwick, E. K. (1991). How to bring your kids up gay. Social Text, (29), 18-27. https://doi.org/10.2307/466296

Vergueiro, V. (2015). Por inflexões decoloniais de corpos e identidades de gênero inconformes: Uma análise autoetnográfica da cisgeneridade como normatividade (Dissertação de mestrado). Programa de Pos Graduacao em Cultura e Sociedade, Universidade Federal da Bahia, Salvador, BA, Brasil. 


\section{Luan Carpes Barros Cassal}

Doutor em Psicologia pela Universidade Federal Fluminense (UFF), Niterói - RJ. Brasil. Pesquisador na The University of Manchester (UoM), Manchester - Inglaterra. Reino Unido.

E-mail: luancassal@gmail.com

(iD https://orcid.org/0000-0003-4237-3270

Héder Lemos Bello

Graduado em Psicologia pela Universidade Federal Fluminense (UFF), Niterói - RJ. Brasil.

E-mail: hederbello86@gmail.com

iD https://orcid.org/0000-0003-4916-4308

\section{Pedro Paulo Gastalho de Bicalho}

Doutor em Psicologia pela Universidade Federal do Rio de Janeiro (UFRJ). Professor do Programa de Pós- Graduação em Psicologia da Universidade Federal do Rio de Janeiro (UFRJ), Rio de Janeiro - RJ. Brasil.

E-mail: ppbicalho@ufrj.br

(iD) https://orcid.org/0000-0003-1986-4338

Observação: O presente trabalho foi realizado com apoio da Coordenação de Aperfeiçoamento de Pessoal de Nível Superior - Brasil (CAPES) - Código de Financiamento 001, através da Bolsa de Doutorado do Programa de Demanda Social no Programa de Pós- Graduação em Psicologia da Universidade Federal Fluminense (UFF).

Endereço para envio de correspondência:

Programa de Pós- Graduação em Psicologia, Instituto de Psicologia, Pavilhão Nilton Campos - Av. Pasteur, 250 Urca, Rio de Janeiro - RJ, Brasil. CEP: 22290-240.

Recebido 10/09/2019

Aceito 04/10/2019

Received 09/10/2019

Approved 10/04/2019

Recibido 10/09/2019

Aceptado 04/10/2019

Como citar: Cassal, L. C. B., Bello, H. L., \& Bicalho, P. P. G. (2019). Enfrentamento à LGBTIfobia, afirmação ético-política e regulamentação profissional: 20 anos da Resolução CFP no 01/1999. Psicologia: Ciência e Profissão, 39 (n.spe 3.), 113-128. ttps:// doi.org/10.1590/1982-3703003228516

How to cite: Cassal, L. C. B., Bello, H. L., \& Bicalho, P. P. G. (2019). Coping with LGBTIphobia, ethical-political affirmation and professional regulation: 20 Years of CFP Resolution 01/1999. Psicologia: Ciência e Profissão, 39 (nspe.3), 113-128. https:// doi.org/10.1590/1982-3703003228516

Cómo citar: Cassal, L. C. B., Bello, H. L., \& Bicalho, P. P. G. (2019). Enfrentamiento a la LGBTIfobia, declaración ético-política y regulación profesional: 20 Años de la Resolución CFP 01/1999. Psicologia: Ciência e Profissão, 39 (nspe.3), 113-128. https:// doi.org/10.1590/1982-3703003228516 